\title{
Health care providers knowledge, attitudes and perceived barriers towards emergency contraception in a sub-Himalayan state of India
}

\author{
Rajiv Kumar Gupta ${ }^{1 *}$, Bhavna Langer ${ }^{1}$, Parveen Singh ${ }^{1}$, Rashmi Kumari ${ }^{1}$, \\ Najma Akhtar ${ }^{1}$, Riya Gupta ${ }^{2}$
}

\begin{abstract}
${ }^{1}$ Department of Community Medicine, Government Medical College, Jammu, Jammu and Kashmir, India ${ }^{2}$ Department of Community Medicine, Acharya Shri Chander College of Medical Sciences and Hospital, Sidhra, Jammu, Jammu and Kashmir, India
\end{abstract}

Received: 31 May 2018

Accepted: 28 June 2018

\section{*Correspondence:}

Dr. Rajiv Kumar Gupta,

E-mail: rajivguptagmc@ rediffmail.com

Copyright: () the author(s), publisher and licensee Medip Academy. This is an open-access article distributed under the terms of the Creative Commons Attribution Non-Commercial License, which permits unrestricted non-commercial use, distribution, and reproduction in any medium, provided the original work is properly cited.

\begin{abstract}
Background: Emergency Contraception (EC) is a method of contraception used within 72 hours of unprotected sex to prevent unwanted pregnancy. More than ten years since its use, a study was conducted among health care providers to assess their knowledge, attitudes and perceived barriers towards EC.

Methods: The current cross-sectional study was conducted among the health care providers (HCPs) in all the health institutions of Jammu city, one of which included a tertiary care teaching hospital. The HCPs for the purpose of the current study included Medical Officers (MOs), Lady Health Visitors/ Staff Nurses (LHV/ SNs) and pharmacists. A 24 item pre-tested questionnaire was administered to the respondents to gather the relevant information.

Results: MOs and LHV/SNs were found to have better knowledge than the pharmacists. Higher proportion of LHV/SNs and pharmacists were willing to learn more about EC $(\mathrm{p}<0.05)$. About two-third of MOs and LHV/SNs agreed about shortage of time during clinic schedule to counsel the users about $\mathrm{EC}(\mathrm{p}<0.05)$.

Conclusions: Gaps in the knowledge of the respondents need to be taken care of with continuing in-service trainings along with behaviour change communication. Role of pharmacists as health care provider especially in the context of family welfare services needs to be reassessed.
\end{abstract}

Keywords: Attitude, Emergency contraception, Health care provider, Knowledge

\section{INTRODUCTION}

The first national study of the incidence of abortion and unintended pregnancy in India, has estimated that in the year 2015, a total of 15.6 million abortions were performed. It thus translated to an abortion rate of 47 per 1,000 women in the age group of 15-49 years. In about $81 \%$ of these cases, medical methods of abortion were the most commonly preferred method. The data further deciphered that the incidence of unintended pregnancy in India was about half of the total pregnancies (a total of 48.1 million pregnancies in 2015). Estimates showed that unintended pregnancy rate in India was 70 per 1,000 women aged 15-49 in the year 2015. ${ }^{1}$ The unsafe medical abortions that account for $8-20 \%$ of all maternal deaths occur as a consequence of unintended pregnancy. ${ }^{2}$ The use of Emergency Contraceptives (EC) worldwide has played a significant role in preventing unintended pregnancies and abortions and this is owing to its potential to reduce maternal mortality and morbidity caused by unsafe abortion.

Recognising the significance of Emergency Contraceptives in Reproductive health of women, many 
countries have not only recognized EC as a contraceptive method but have also implemented measures to promote access to it. In India Department of Health introduced emergency contraceptive pill (E- pills) in the National Family Welfare Programme during the year 2002-03 and later in the year 2005, declared it as an over the counter (OTC) product. ${ }^{3}$ This contraceptive is to be used within 72 hours of unprotected sex and is provided free of cost to states and UTs. Under the national family welfare programme in India, it is being delivered to the beneficiaries at rate of Rs 2 per tablet. ${ }^{4}$

In spite of all efforts, EC still remains a mostly underutilized option in the prevention of pregnancy. The main reason for this is the knowledge gaps of both the health care providers and the beneficiaries which can negatively impact the prescribing habits and future promotion of emergency contraception. ${ }^{5}$ Female health workers have an integral role in the provision of health services to the community not only as service providers but also as health educators. They are a reliable source of information to women in the reproductive age group and can play a pivotal role in behaviour change communication. They have an influence on women's contraceptive behaviour. This is only possible if the health care providers are trained and updated to the latest issues as their knowledge, attitudes and practices towards ECPs can not only promote but sometimes even impede the use of ECP among beneficiaries. It has been more than a decade that EC is being provided in government health institutions and review of literature revealed dearth of studies among health care providers about EC knowledge and attitude in our state of $\mathrm{J}$ and $\mathrm{K}$. So, the authors planned to explore the knowledge, attitude and barriers of health care providers towards EC use in Jammu city of $\mathrm{J}$ and $\mathrm{K}$, India.

\section{METHODS}

The present cross-sectional survey was conducted in the month of January 2018 among the health care providers in Jammu city of J\&K state, India. The health care providers in the current study included Medical officers (MOs), Lady Health Visitors (LHVs)/staff nurses (SNs) and Pharmacists working in the all the health institutions of the city of Jammu. The participants provided care in all the health institutions of Jammu city, one of which was a tertiary care teaching hospital. Due permission was sought from institutional ethical committee of Govt Medical College, Jammu before conducting the study.

The survey instrument consisted of a two-page questionnaire which was developed specifically for the current study by the authors through an extensive search of the literature. The survey instrument so developed was pilot tested on a group of 20 health care providers who weren't part of the actual study sample. The feedback so obtained was incorporated and finally a 24-item questionnaire was prepared for use.
The survey instrument had questions on various aspects of emergency contraception including Knowledge, attitudes and perceived barriers. The first part of the instrument collected demographic information of the participants. The second part elicited information on knowledge, attitude and barriers to emergency contraception use. Informed consent and confidentiality were ensured by including a paragraph of informed consent at the beginning of the questionnaire.

A total of 250 survey instruments were distributed among the health care providers out of which 230 were retrieved on the day of collection. Further it was found that ten questionnaires were incomplete and were left out. Thus, the final tally for analysis was 220 respondents.

\section{Statistical analysis}

The data thus collected was analysed and tabulated. Test of significance used was chi-square and p-value $<0.05$ was considered significant.

\section{RESULTS}

A total of 220 survey instruments were received by the authors on the day of collection thus eliciting a response rate of $88 \%(220 / 250)$. Majority of the respondents were males $(63.63 \%)$ and $81 \%$ of them were working in the general hospital. Among the respondents, occupation wise distribution was Medical officers (40.90\%), LHVs/SNs (36.38\%) and pharmacists (22.72\%). More than half of the respondents had working experience of less than ten years signifying a shorter period of service and almost an equal number of respondents were unmarried as per their marital status (Table 1).

Table 1: Socio demographic profile of the respondents $(n=220)$.

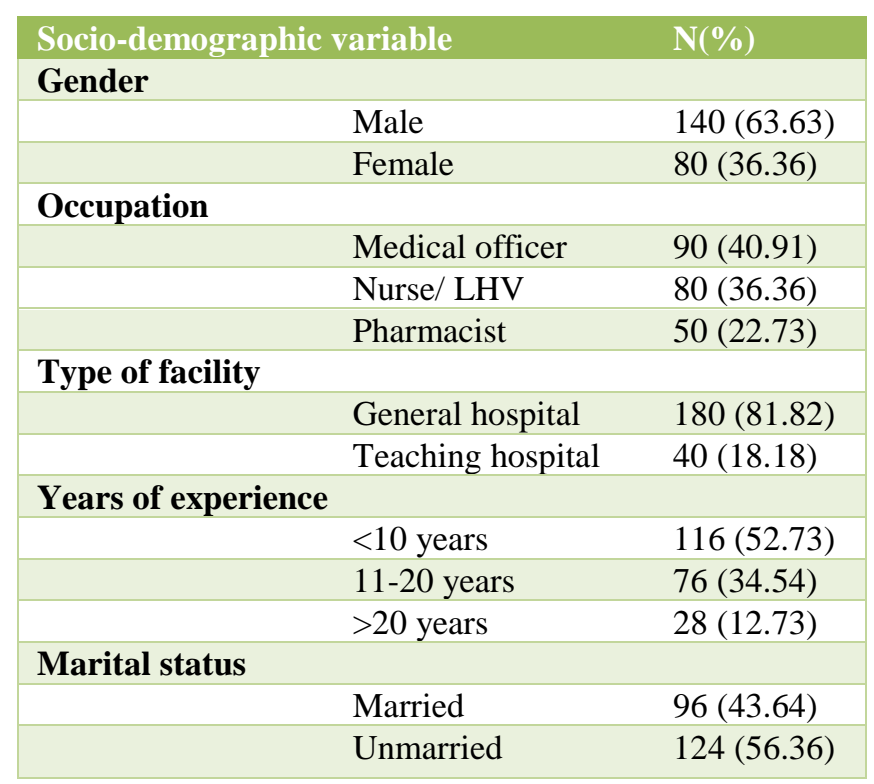


All the health care providers replied in affirmative when asked if they knew about EC.

Regarding the correct time of EC initiation, correct knowledge among Medical officers and LHVs/SNs was $91.11 \%$ and $85 \%$ respectively. Majority of the respondents had knowledge that prior test of pregnancy was not necessary before prescribing EC $(p>0.05)$. Majority of the health care providers had correct knowledge about EC pills to be repeated in case of vomiting by the user within two hours of intake. $88 \%$ of LHVs/SNs replied that they had an opportunity to learn about EC. When enquired about appropriate candidate for
EC use, majority of the respondents correctly picked the women with unprotected sex as the first choice. However inconsistent contraceptive users and women with infrequent sex were also chosen though with lesser frequency. Regarding knowledge about indications for EC use, results revealed that medical officers and LHVs/SNs had better knowledge in comparison to pharmacists though it was not significant statistically ( $p>0.05$ ). Knowledge about action of pills was found to be good among MOs and LHVs/SNs in comparison to pharmacists and this difference was found to be statistically significant $(\mathrm{p}<0.05)$ (Table 2$)$.

Table 2: Knowledge of respondents regarding emergency contraception $(n=220)$.

\begin{tabular}{|c|c|c|c|c|c|c|}
\hline Question & Response & $\begin{array}{l}\text { Medical } \\
\text { officer (90) }\end{array}$ & $\begin{array}{l}\text { LHV/SN } \\
(80)\end{array}$ & $\begin{array}{l}\text { Pharmacist } \\
\text { (50) }\end{array}$ & Total (220) & $\begin{array}{l}P \\
\text { value }\end{array}$ \\
\hline \multirow{2}{*}{ Do you know about EC } & Yes & $90(100)$ & $80(100)$ & $50(100)$ & $220(100)$ & \multirow{2}{*}{-} \\
\hline & No & $00(00)$ & $00(00)$ & $00(00)$ & $00(00)$ & \\
\hline \multirow{2}{*}{$\begin{array}{l}\text { Correct time of initiation of } \\
\text { EC is within } 72 \text { hours of } \\
\text { unprotected sex }\end{array}$} & Yes & $82(91.11)$ & $68(85.00)$ & $24(48)$ & $174(79.09)$ & \multirow[b]{2}{*}{0.00} \\
\hline & No & $08(8.89)$ & $12(15.00)$ & $26(52)$ & $46(20.91)$ & \\
\hline \multirow{2}{*}{$\begin{array}{l}\text { Is pregnancy test necessary } \\
\text { before prescribing EC }\end{array}$} & Yes & $02(2.22)$ & $06(7.50)$ & $06(12)$ & $206(93.64)$ & \multirow{2}{*}{0.06} \\
\hline & No & $88(97.78)$ & $74(92.50)$ & $44(88)$ & $14(6.36)$ & \\
\hline \multirow{2}{*}{$\begin{array}{l}\text { Should EC pill be repeated } \\
\text { if a woman has vomiting } \\
\text { within two hours of intake }\end{array}$} & Yes & $80(88.89)$ & $70(87.50)$ & $30(60)$ & $180(81.82)$ & \multirow[b]{2}{*}{0.00} \\
\hline & No & $10(11.11)$ & $10(12.50)$ & $20(40)$ & $40(18.18)$ & \\
\hline \multirow{2}{*}{$\begin{array}{l}\text { Did you have an opportunity } \\
\text { to learn about EC }\end{array}$} & Yes & $70(77.78)$ & $71(88.75)$ & $15(30)$ & $156(70.91)$ & \multirow{2}{*}{0.00} \\
\hline & No & $20(22.22)$ & $09(11.25)$ & $35(70)$ & $64(29.09)$ & \\
\hline \multirow{4}{*}{$\begin{array}{l}\text { *Appropriate candidate for } \\
\text { EC use }\end{array}$} & $\begin{array}{l}\text { Women with } \\
\text { unprotected sex }\end{array}$ & $82(91.11)$ & $74(92.50)$ & $32(64.00)$ & $188(85.45)$ & \multirow{4}{*}{0.20} \\
\hline & $\begin{array}{l}\text { Inconsistent } \\
\text { contraceptive users }\end{array}$ & $62(68.89)$ & $46(57.50)$ & $36(72.00)$ & $144(65.45)$ & \\
\hline & $\begin{array}{l}\text { Women with } \\
\text { infrequent sex }\end{array}$ & $40(44.44)$ & $38(47.50)$ & $24(48.00)$ & $102(46.36)$ & \\
\hline & $\begin{array}{l}\text { Women with } \\
\text { multiple partners }\end{array}$ & $16(17.78)$ & $27(33.75)$ & $12(24.00)$ & $55(25.00)$ & \\
\hline \multirow{4}{*}{ *Indications for EC use } & Rape & $78(86.67)$ & $72(90.00)$ & $24(48.00)$ & $174(79.09)$ & \multirow{4}{*}{0.17} \\
\hline & $\begin{array}{l}\text { Unprotected } \\
\text { intercourse }\end{array}$ & $72(80.00)$ & $74(92.50)$ & $32(64.00)$ & $178(80.90)$ & \\
\hline & Condom breakage & $70(77.78)$ & $70(77.78)$ & $16(32.00)$ & $156(70.90)$ & \\
\hline & Missed pills & $62(68.89)$ & $72(90.00)$ & $12(24.00)$ & $146(66.36)$ & \\
\hline \multirow{3}{*}{ *Action of pills } & Prevent pregnancy & $82(91.11)$ & $72(90.00)$ & $20(40.00)$ & $154(70.00)$ & \multirow{3}{*}{0.00} \\
\hline & Induce abortion & $08(08.88)$ & $12(15.00)$ & $16(32.00)$ & $46(20.90)$ & \\
\hline & Both & $27(30.00)$ & $24(30.00)$ & $14(28.00)$ & $65(29.54)$ & \\
\hline
\end{tabular}

* Multiple answers

Among the attitudes, majority of Medical officers and LHVs/SNs felt that benefits of EC outweighed the risks $(p<0.05)$. Regarding increase in promiscuity due to EC use, majority of the respondents replied in affirmative though it was not found to be statistically significant $(\mathrm{p}>0.05)$.

About $30 \%$ of the pharmacists would refer a case to gynaecologist for prescription of EC which reflected the lack of self-confidence. Among the health care providers,
LHVs/SNs and pharmacists were interested to learn more about EC and also agreed that EC should be more widely advertised $(\mathrm{p}<0.05)$ (Table 3$)$. Majority of health care providers didn't feel uncomfortable prescribing EC on religious or ethical grounds.

Among the pharmacists, $76 \%$ reported that birth defects/side effects due to EC use was a perceived barrier and it was also statistically significant $(\mathrm{p}<0.05)$. Another barrier reported by $74 \%$ of the pharmacists was 
inexperience in EC use. Regarding shortage of time to counsel about the EC to the users, about two-third of MOs and LHVs/SNs replied in the affirmative. Another perceived barrier reported by majority of the MOs and LHV/SNs was that they didn't feel liking discussing EC after the unprotected intercourse $(\mathrm{p}<0.05)$ (Table 4).

Table 3: Attitudes and beliefs of respondents regarding EC $(n=220)$.

\begin{tabular}{|c|c|c|c|c|c|c|}
\hline Question & Response & $\begin{array}{l}\text { Medical office } \\
(90)\end{array}$ & LHV/SN(80) & $\begin{array}{l}\text { Pharmacist } \\
\text { (50) }\end{array}$ & Total (220) & $\begin{array}{l}P \\
\text { value }\end{array}$ \\
\hline \multirow{2}{*}{$\begin{array}{l}\text { Do you feel that benefits of } \mathrm{EC} \text { out } \\
\text { weight the risks }\end{array}$} & Yes & $82(91.11)$ & $74(92.5)$ & $27(54)$ & $183(83.18)$ & \multirow{2}{*}{0.00} \\
\hline & No & $8(8.88)$ & $06(7.5)$ & $23(46)$ & $37(16.82)$ & \\
\hline \multirow{2}{*}{$\begin{array}{l}\text { Does EC use increases promiscuity } \\
\text { and misuse }\end{array}$} & Yes & $75(83.33)$ & $64(80)$ & $37(74)$ & $176(80.00)$ & \multirow{2}{*}{0.41} \\
\hline & No & 15 (16.67) & $16(20)$ & $13(26)$ & $44(20.00)$ & \\
\hline \multirow{2}{*}{$\begin{array}{l}\text { Is EC use appropriate for discussion } \\
\text { during routine consultation }\end{array}$} & Yes & $60(66.67)$ & $70(87.5)$ & $20(40)$ & $150(68.18)$ & \multirow{2}{*}{0.00} \\
\hline & No & $30(33.37)$ & $10(12.5)$ & $30(60)$ & $70(31.82)$ & \\
\hline \multirow{2}{*}{$\begin{array}{l}\text { Would you refer a case to } \\
\text { Gynecologist for prescription of EC }\end{array}$} & Yes & $12(13.33)$ & $06(7.5)$ & $15(30)$ & $187(85.00)$ & \multirow{2}{*}{0.00} \\
\hline & No & $78(86.6)$ & $74(92.5)$ & $35(70)$ & $33(15.00)$ & \\
\hline \multirow{2}{*}{$\begin{array}{l}\text { Are you interested in learning more } \\
\text { about EC }\end{array}$} & Yes & $40(44.44)$ & $68(75.56)$ & $42(84)$ & $150(68.18)$ & \multirow{2}{*}{0.00} \\
\hline & No & $50(55.56)$ & $12(24.44)$ & $08(16)$ & $70(31.82)$ & \\
\hline \multirow{2}{*}{$\begin{array}{l}\text { Should EC be more widely } \\
\text { advertised }\end{array}$} & Yes & $64(71.11)$ & $66(82.5)$ & $46(92)$ & $176(80.00)$ & \multirow{2}{*}{0.00} \\
\hline & No & $26(28.89)$ & $14(17.5)$ & $04(8)$ & $44(20.00)$ & \\
\hline
\end{tabular}

Table 4: Perceived barriers regarding EC $(n=220)$.

\begin{tabular}{|c|c|c|c|c|c|c|}
\hline Question & Response & $\begin{array}{l}\text { Medical } \\
\text { officer }(90)\end{array}$ & $\begin{array}{l}\text { LHV/SN } \\
(80)\end{array}$ & $\begin{array}{l}\text { Pharmacist } \\
\text { (50) }\end{array}$ & Total (220) & $\begin{array}{l}P \\
\text { value }\end{array}$ \\
\hline \multirow{2}{*}{$\begin{array}{l}\text { Do you feel uncomfortable prescribing } \\
\text { EC for religious/ethical reason }\end{array}$} & Yes & $25(27.78)$ & $14(17.5)$ & $27(54)$ & $66(30.00)$ & \multirow{2}{*}{0.00} \\
\hline & No & $65(72.22)$ & $66(82.5)$ & $23(46)$ & $154(70.00)$ & \\
\hline \multirow{2}{*}{$\begin{array}{l}\text { Are you concerned about birth } \\
\text { defects/side effects due to EC use }\end{array}$} & Yes & $06(6.67)$ & $04(5)$ & $38(76)$ & $48(21.82)$ & \multirow{2}{*}{0.00} \\
\hline & No & $84(93.33)$ & $76(95)$ & $12(24)$ & $172(78.18)$ & \\
\hline \multirow{2}{*}{$\begin{array}{l}\text { Are you reluctant to prescribe EC } \\
\text { because of inexperience with its use }\end{array}$} & Yes & $05(5.55)$ & $04(5)$ & 37 (74) & $46(20.91)$ & \multirow{2}{*}{0.00} \\
\hline & No & $85(94.44)$ & $76(95)$ & $13(26)$ & $174(79.09)$ & \\
\hline \multirow{2}{*}{$\begin{array}{l}\text { Are you short of time in your clinic } \\
\text { schedule to counsel about EC }\end{array}$} & Yes & $60(67.67)$ & $58(72.5)$ & $15(30)$ & $133(60.45)$ & \multirow{2}{*}{0.00} \\
\hline & No & $30(33.34)$ & $22(27.5)$ & $35(70)$ & $87(39.55)$ & \\
\hline \multirow{2}{*}{$\begin{array}{l}\text { It doesn't occur to me to discuss EC } \\
\text { after unprotected sex }\end{array}$} & Yes & $76(84.44)$ & $63(78.75)$ & $19(38)$ & $158(71.82)$ & \multirow{2}{*}{0.00} \\
\hline & No & $14(15.5)$ & $17(21.25)$ & $31(62)$ & $62(28.18)$ & \\
\hline
\end{tabular}

\section{DISCUSSION}

Despite E-pills being available free of cost in government health centres across the country, inadequate knowledge of the health care providers remains a limiting factor in dispensing the $\mathrm{EC}$ to the beneficiaries.

Among the health care providers, the results revealed that all of them had known EC. These results are not identical to the results reported by Kishore $\mathrm{V}$ et al in study conducted in Delhi where MOs were more knowledgeable than other health care providers. ${ }^{6}$

In the current study, $91 \%$ of MOs and $85 \%$ of LHVs /SNs had correct knowledge about time of initiation of EC after unprotected sex whereas only one-third of the respondents were aware of the correct time in the study conducted by Wallace JL et al. ${ }^{7}$

In a study conducted in Nigeria, Ebuehi OM et al reported that only half of the respondents knew the correct time frame for effective use of EC. ${ }^{8} 70 \%$ of the respondents in the current study knew that EC prevents pregnancy but $20.90 \%$ believed that they act as an abortifacient. These results are in agreement with the results reported by Ebuehi OM et al from Nigeria. ${ }^{8}$

Similarly, Wallace JL et al reported that only $56 \%$ respondents answered that EC was not an abortifacient. $^{7}$ So, it would be pertinent to mention that gaps in knowledge about EC among health care providers were not specific to India alone. Present study results are in congruence to studies conducted in India by Kishore V et a and also studies conducted abroad by Ebuehi OM et al from Nigeria, Sevil U et al from Turkey and Wallace JL et al from Michigan, USA. ${ }^{6-9}$

Attitudes and beliefs of majority of health care providers were positive in the current study except for increase in EC use may promote misuse and promiscuity. In comparison to $83.3 \%$ of Medical officers in the current study, Kishore $\mathrm{V}$ et al reported that $55 \%$ of the Medical 
officers stated that $E$ pill usage would increase promiscuity and misuse among the users, especially the younger generation and thus disagreed for its advance provisioning and availability as on OTC product. ${ }^{6}$ Other studies have also reported that easy access to EC would encourage unsafe sexual relations and discourage the use of more reliable contraception. ${ }^{10,11}$

Among the perceived barriers shortage of time in clinic schedule to counsel the clients and EC was reported by two third of Medical Officers and LHVs/SNs. Another major barrier reported was not able to discuss EC especially after the unprotected sex. Wallace JL et al reported one of the most significant barriers was not remembering to discuss EC during routine visits. ${ }^{7}$ Abdulghani HM et al reported that barrier to the use of EC were promiscuity $(31 \%)$, religious ethic reasons (27\%) and teratogenicity (44\%).

Routine discussion of EC during reproductive health visits could inform women of the existence of EC and may lower inhibitions about requesting it. ${ }^{12}$ The authors suggest use of posters and pamphlets in the clinic to invite women to discuss EC.

Among the health care providers, those with training in contraception were found to possess better knowledge and attitude. In this connection, the LHVs/SNs fared much better on many parameters of knowledge and attitude. This typically is also a reflection of Indian Social system and prevalent inhibition leading to a preference among female patients to preferably consult a female health care provider.

Pharmacist who constitute a major category of health care providers reported very low level of knowledge about EC in comparison to LHVs/SNs. It may be due to their everincreasing workload of dispensing drugs but not the contraceptives, their selective engagement and work assignment are probably the reasons for low levels of knowledge about EC.

Gaps in knowledge among pharmacists on EC were also reported by Riper KV et al who suggested that they be provided opportunities to practice counselling on ECs in the form of both formal and continuing medical education. ${ }^{13}$ Saxena $\mathrm{P}$ et al also reported dismal picture on the role of pharmacists in dispensing EC as none of them asked about the time lapsed since last unprotected sexual intercourse or last menstrual period before deciding the eligibility of the client. ${ }^{14}$

Effective educational interventions are likely to improve provider's knowledge and subsequent provision of the EC as it has a considerable potential to prevent unintentional pregnancies especially among adolescents who constitute vast majority of sexually active population.
Since the study was conducted in urban settings in health care institutions including a tertiary care teaching hospital, the results lack generalization.

\section{CONCLUSION}

Correct Knowledge and a positive attitude go on a long way for effective dispensation of EC which, of late have become a cornerstone of Family Planning Programme. Although Medical Officers and LHVs/SNs knowledge and attitude were found to be adequate but role of pharmacists as health care provider vis-a-vis family welfare service needs to be reassessed by policy makers. Authors further suggest in service training to improve technical knowledge along with behaviour change communication to positively modulate the mind set of health care providers.

\section{Funding: No funding sources}

Conflict of interest: None declared

Ethical approval: The study was approved by the Institutional Ethics Committee

\section{REFERENCES}

1. Singh S, Shekhar C, Acharya R, Moore AM, Stillman M, Pradhan MR, Frost JJ, Sahoo H, Alagarajan M, Hussain R, Sundaram A. The incidence of abortion and unintended pregnancy in India, 2015. Lancet Global Health. 2018;6(1):e11120.

2. Armo M, Babbar K, Thakur H, Pandey S. Maternal morbidity due to unsafe medical abortion in rural practice is just the tip of the iceberg: is it really preventable?. Int $\mathrm{J}$ Reprod Contracept Obstet Gynecol. 2017;4(1):56-60.

3. Nivedita K, Fatima Shanthini N. Knowledge, attitude and practice of emergency contraception on nursing personnel. J Clin Diagn Res. 2014;8(9):OC20-22.

4. Family Planning. Ministry of Health and Family Welfare. Annual report2017-18. Chapter 6:95. Available at: https://mohfw.gov.in/sites/default/files/6201617.(last assessed 21.05.2018).

5. Sharma C. Understanding of emergency contraception among nursing staff in a tertiary care hospital of Andaman and Nicobar Islands, India. J Basic Clin Reprod Sci. 2017;6(1):133-6.

6. 6. Kishore V, Misro MM, Nandan D. Providers knowledge, attitude and dispensing practices of Epills in government dispensaries of south district in Delhi, India. Ind J Commn Med. 2010; 35(1):46-51.

7. Gorenflo DW, Fetters MD. Emergency contraception: knowledge and attitudes of family medicine providers. Fam Med. 2004;36(6):417-22.

8. Ebuehi OM, Ebuehi OA, Inem V. Health care providers' knowledge of, attitudes toward and provision of emergency contraceptives in Lagos, Nigeria. Int Family Plann Perspectives. 2006;32:8993. 
9. Sevil U, Yanikkerem E, Hatipoglu S. A survey of knowledge, attitudes and practices relating to emergency contraception among health workers in Manisa, Turkey. Midwifery. 2006;22(1):66-77.

10. Grimes DA. Switching emergency contraception to over-the-counter status. N Eng J Med. 2002;347(11):846-9.

11. Glasier A, Baird D. The effects of self-administering emergency contraception. $\mathrm{N}$ Eng $\mathrm{J}$ Med. 1998;339(1):1-4.

12. Abdulghani HM, Karim SI, Irfan F. Emergency contraception : knowledge and attitude of family physicians of a teaching hospital, Karachi, Pakistan. J Health Popul Nutr 2009;27(3):339-344.

13. Van KK. Emergency contraceptive pills: dispensing practices, knowledge and attitudes of South Dakota pharmacists. Perspectives Sexual Reprod Health. 2005;37(1):19-24.

14. Saxena P, Mishra A, Nigam A. Evaluation of pharmacists services for dispensing Emergency contraceptive pills in Delhi, India: a mystery shopper study. Ind J Commn Med. 2016;41(3):198-202.

Cite this article as: Gupta RK, Langer B, Singh P, Kumari R, Akhtar N, Gupta R. Health care providers knowledge, attitudes and perceived barriers towards emergency contraception in a sub-Himalayan state of India. Int J Reprod Contracept Obstet Gynecol 2018;7:3244-9. 